\title{
AS COLEÇÕES DIGITAIS ESPECIAIS: O CASO CEDOC DA FACULDADE DE COMUNICAÇÃO DA UNB
}

\author{
Mônica Regina Peres \\ Bibliotecária \\ Doutoranda em Ciência da Informação - PPGCI-UnB \\ mperes.bsb@gmail.com \\ Antônio Miranda \\ Professor Emérito - UnB \\ Doutor em Ciências da Informação \\ antmiranda@hotmail.com
}

\section{Resumo}

\begin{abstract}
O Centro de Documentação (CeDoc) da Faculdade de Comunicação da Universidade de Brasília reúne a memória da produção acadêmica e experimental da Faculdade a partir de um projeto de construção de um espaço laboratorial, transdisciplinar, para a investigação e criação de propostas de Gestão da Memória em Comunicação e Informação da Faculdade de Comunicação. Relata as ações para a criação da coleção especial da FAC nos repositórios da Biblioteca Central (BCE), planejada e discutida durante a disciplina optativa Comunicação, Informação e Computação: fundamentos e aplicação. As ações de preservação são: 1. Organização e digitalização das edições da revista Campus Repórter Campus Repórter; 2. Organização e digitalização do jornal Campus impresso; 3. Livro Livre - sala de leitura de uso e manutenção compartilhada. Elaboração de normas, tutoriais e manuais para o desempenho das atividades. O projeto em sua totalidade ainda está em fase de implantação.
\end{abstract}

Palavras-chave: Informação; Computação; Comunicação; Repositórios de informação; Coleções Especiais.

\section{INTRODUÇÃO}

A Faculdade de Comunicação (FAC) unidade acadêmica da Universidade de Brasília (UnB) é um exemplo em geração de produtos não vinculados à conclusão de curso e possui um Centro de Documentação (CEDOC) para receber essas produções. No texto de Mazzoni et al (2001, p.29-30) fala se sobre a necessidade da relação entre ambientes universitários, conhecimento e informação, onde ter acesso à informação é algo indissociável da educação e lazer e direito de todos. Sobre essa perspectiva, viu-se a necessidade em tornar essa produção acadêmica em uma coleção especial vinculada a Biblioteca Central (BCE) da UnB, assim compondo o acervo da biblioteca universitária da instituição e possibilitando a preservação desse bem informacional.

No texto de Vergueiro (1993), encontramos a definição de Biblioteca Universitária, quando considera o modelo desenvolvido por Evans:

Bibliotecas universitárias - Devem atender aos objetivos da universidade, a Bibliotecas universitárias - Devem atender aos objetivos da universidade, a saber, o ensino, a pesquisa e a extensão de serviços à comunidade. Isto vai exigir, quase que necessariamente, uma coleção com forte tendência ao crescimento, pois atividades de pesquisa exigem uma variada gama de materiais de informação que possibilitem ao pesquisador ter acesso a tocos os pontos de vista importantes ou necessários para sua pesquisa. [...] Isso é decorrente de que a mesma necessita ter um volume de materiais suficientemente significativo em termos de quantidade e qualidade para dar suporte às atividades de pesquisa realizadas tanto em nível de graduação como de pós, assim como às atividades normais de prestação de serviços ou extensão à comunidade. 
Ao adotarmos a definição acima, onde a biblioteca universitária está sempre em crescimento, podemos dizer que fatores relativos à qualidade e quantidade devem estar presentes no planejamento de constituição do acervo. Segundo Parmeshwaram, (1997 apud KHAN; KHAN, 2010, p. 5), o desenvolvimento de coleções não é uma simples atividade:

O desenvolvimento de coleções inclui o planejamento de uma construção sistemática e racional da coleção geral. O processo inclui diversas atividades, tais como as necessidades dos usuários, a avaliação das coleções atuais, a determinação de uma política de seleção, gestão de itens selecionados, a análise e o armazenamento de itens da coleção, incorporadas ao planejamento e compartilhamento de recursos. Assim, o desenvolvimento de coleções não é uma atividade singular, mas um grupo de atividades.

Este artigo trata sobre a criação das Coleções Especiais no CeDoc da FAC/UnB e a sua relação com as questões de preservação de produção acadêmica própria, o que contribuirá para preencher a lacuna na literatura sobre constituição de coleções especiais. As atividades propostas e realizadas, deverão contribuir para melhorar o desempenho dos discentes e os acervos das BUs e consequentemente servir como diferencial acadêmico das IFES.

No texto de Khan; Khan (p. 5, 2010) encontramos a seguinte definição:

Gerenciamento de coleções é muito mais do que o desenvolvimento de coleções, porque envolve vários aspectos gerenciais, tais como dotação orçamental, a avaliação do acesso à informação, condições de armazenagem e utilização, organização, aplicação de métodos de preservação e conservação, e também quando necessário, o monitoramento de acesso para a melhor utilização dos recursos de informação. Ela não só envolve o desenvolvimento de coleções, mas também a apresentação das coleções para os usuários.

E continuam mais adiante afirmando quanto ao planejamento:
O desenvolvimento de coleções é um plano que pode ser implementado e avaliado. $\mathrm{O}$ processo envolve principalmente três aspectos:

1. Planejamento do acervo - um design para adquirir documentos;

2. Implementação do acervo - processo de tornar os documentos disponíveis;

3. Avaliação do acervo - análise e julgamento da relevância em relação às metas e objetivos. (KHAN; KHAN, p. 6, 2010)

Para tornar possível essa pesquisa, houve a necessidade de planejamento detalhado, para acessar e conhecer o Centro de Documentação (CeDoc) da Faculdade de Comunicação (FAC) da Universidade de Brasília (UnB), identificado como CeDoc-FAC, que é reconhecido como um Laboratório Transdisciplinar de Pesquisa e Gestão da Memória na Comunicação, no qual se situa este estudo quanto à formação de acervos especiais, de forma cooperativa entre a unidade que produz conhecimento e a unidade responsável pela preservação em repositório público, acessível a toda a sociedade. O processo de organização das coleções teve início com o projeto ComClick - Integração de TICs ao processo de ensino-aprendizagem, (Edital CAPES 15/2010) coordenado pela professora Dra. Dione de Oliveira Moura. O acervo da unidade é o resultado da produção intensa e diversificada de atividades teóricas e práticas de várias disciplinas distribuídas nos 04 cursos que a faculdade abriga, mas que estavam armazenadas de maneira incorreta, tanto do ponto de vista físico, quanto de disponibilidade em rede.

Entre os materiais que estavam armazenados na unidade, foram encontrados vários Trabalhos de Conclusão de Curso, que vão desde os anos 1980 até 2017 que são obrigatórios para a concessão do grau, nas modalidades monografia e produto; das mais de 400 edições do jornal impresso Campus, nascido em 1970 como jornal laboratório e hoje é o mais antigo em circulação periódica no país nesta modalidade, foi encontrado um acervo incompleto; das 19 edições da revista Campus Repórter, de experimentação de texto, imagem e desenho gráfico em grandes reportagens, somente foi resgatado o material impresso, apesar da revista ter formato digital para envio à gráfica; entre outros materiais. Esta pesquisa acontece em torno do $\mathrm{CeDoc}$, 
com o intuito em promover soluções de comunicação, informação e computação para tornar os materiais acadêmicos acessíveis para toda a comunidade acadêmica e outros que se interessarem.

Com a parceria entre a Faculdade de Comunicação e a Biblioteca Central (BCE) da UnB, os objetivos do projeto CeDoc passaram a ser: digitalizar as edições da revista impressa Campus Repórter para disponibilização online de todos os volumes; organização e digitalização do jornal Campus impresso como parte da comemoração dos 50 anos da publicação, o mais antigo jornal-laboratório em circulação no país; a busca de registros, organização e disponibilização em repositórios do material ainda disponível em rede do jornal digital Campus Online. Além da parceria, o CeDoc também tem o objetivo de criar o Livro Livre - sala aberta de leitura para uso e manutenção compartilhada de acervo bibliográfico. Sendo que as coleções especiais da FAC ficarão acessíveis também por APP desenvolvido por bolsistas pagos pelo Fundo de Apoio à Pesquisa (FAP-DF) e alunos do curso de Computação.

Os acervos foram iniciados pela organização da Revista Campus Repórter, elaborados pelos graduandos sob a orientação dos professores. Além das edições impressas, ficaram disponíveis as edições em formato digital, que passa a ter normas de manutenção do acervo, a ser inserido periodicamente no repositório de Coleções Especiais da BCE. O acervo do Jornal Campus, em formato impresso, foi identificado e organizado como parte da comemoração dos 50 anos da publicação, o mais antigo jornal-laboratório em circulação no país, finalizou o ano de 2017 com mais de 400 edições, porém nem todas estão armazenadas ou no CeDoc ou na BCE, ainda há uma longa jornada para recuperação de todas as edições. O Campus Online, tem edições hospedadas em vários locais, além do material guardado pela equipe de informática da FAC, hoje está sob a guarda dos técnicos de TI da faculdade e não possuem relação com o acervamento do CeDoc. O projeto Livro Livre é uma sala de leitura de uso e manutenção compartilhada, onde os livros recebidos em doação pelo CeDoc são oferecidos aos alunos em torno de salas livres de leitura, sem controle de empréstimo, mas como exercício de compartilhamento e de gestão coletiva e colaborativa. As ações foram iniciadas em 2015 sendo que a partir do primeiro semestre 2016 foi possível oferecer a disciplina optativa Comunicação, Informação e Computação: fundamentos e aplicação, com o envolvimento de alunos para a realização das atividades.

Para iniciar as atividades de pesquisa no CEDOC, o que foi possível em março de 2017, encontramos uma sala com estantes deslizantes subutilizadas, ar condicionado precisando de manutenção, mesas e cadeiras em péssimo estado e um vasto volume de materiais acumulados em caixas ou amontoados dentro das estantes. Como demonstrado nas fotos a seguir:

Figura 1 - Sala para processamento

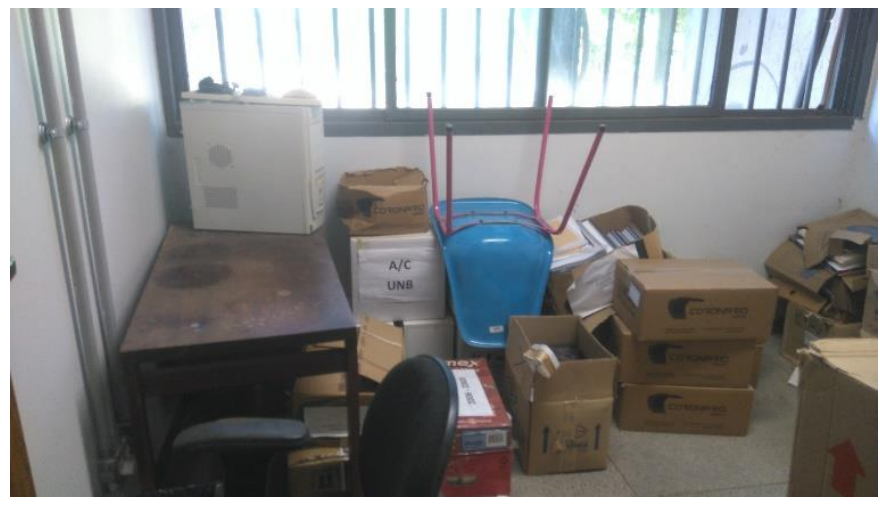

Fonte: PERES, MR 


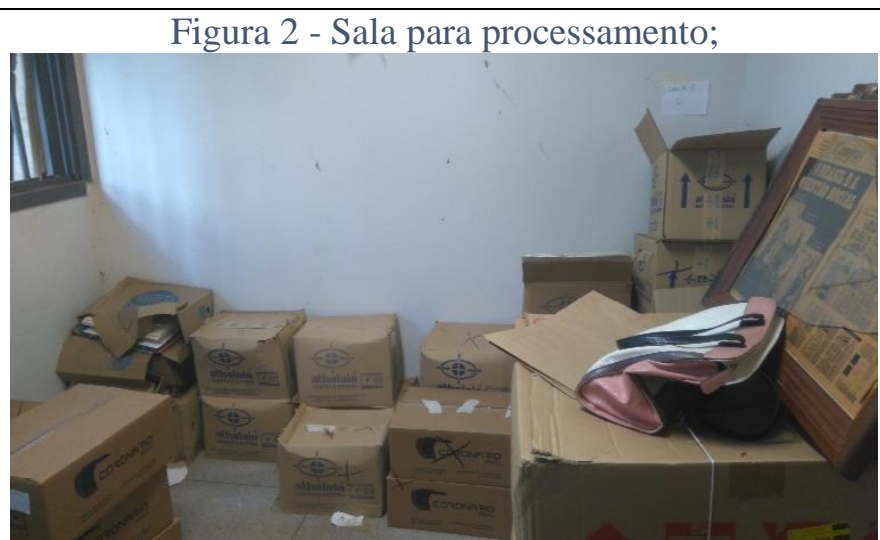

Fonte: PERES, MR

Figura 3- Área para atendimento

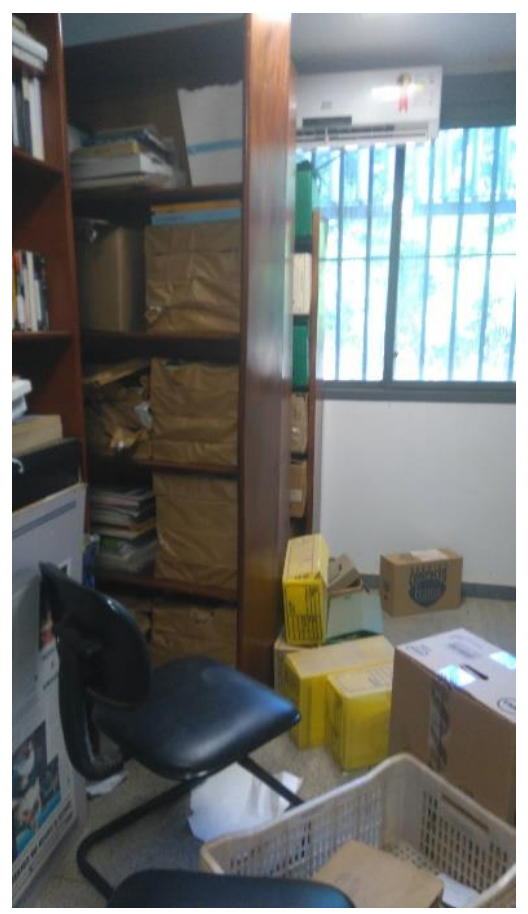

Fonte: PERES, MR

Para identificar os tipos de documentos e seus suportes, foi necessário iniciar $\mathrm{o}$ inventário, onde identificamos muitos documentos administrativos e de secretaria, fotografias, discos de vinil, TCCs (em alguns casos com material/produto em anexo), dissertações, teses, Revista Campus Réporter, Jornal Campus (impresso), livros, revistas, jornais, e documentação audiovisual registrada em vários suportes como DVDs, fitas magnéticas, fitas de vídeo em VHS, em Betacam e em minidv e de imediato os documentos audiovisuais quer eram arquivados nas estantes deslizantes em aço, foram transferidas para estantes de madeira.
Atualmente os materiais de áudio são mantidos na mesma sala, já climatizada com arcondicionado.

A biblioteca não pode ficar alheia as novas formas de linguagem de seus usuários e da produção de seus acervos, deve estar conectada a uma rede, que traz um novo conceito para a armazenagem da informação e para sua disseminação. Essa base conceitual ressalta a necessidade da criação, aquisição, distribuição e armazenamento de documento sob a forma digital. Um acervo em formato digital permite que se tenha também uma cópia em papel, mas a disponibilidade dos conteúdos é ampliada. 
O (a) AV3 é, finalmente, um tipo de linguagem que se apresenta por meio da convergência tecnológica complementada pelo hibridismo de formatos e registros e que desperta uma ação criativa integradora de sentidos. Essa linguagem vem potencializando a composição das estruturas de informação tornando-as mais complexas e ecléticas em termos de conteúdo e ao mesmo tempo cada vez mais 'encantadoras' e sedutoras não somente ao "olhar", mas a uma percepção integrada de todos os sentidos. (MIRANDA; SIMEÃO. p.50, 2014)

As várias formas de linguagem e o hibridismo dos materiais encontrados na FAC, fez com que as coleções fossem criadas por produtos consolidados.

\section{A NECESSIDADE DAS COLEÇÕES ESPECIAIS DO CEDOC/FAC}

Mesmo a informação sendo reconhecida como primordial para as instituições, faz-se necessária de adoção de estratégias que além de satisfazer os usuários, valorizem os serviços e produtos das unidades de informação, segundo Amaral (2008, p. 34).

Apesar de a informação ser considerada o recurso nas organizações da sociedade atual, ela representa uma classe particular dentre os demais recursos. [...].

Isto reforça a adoção do marketing da informação, que recomenda e enfatiza a importância do usuário como cliente consumidor de informação e a adequação da oferta dos produtos e serviços de informação aos interesses e necessidades desses usuários. Clientes cada vez mais exigentes vão considerar os produtos e serviços informacionais oferecidos em função do valor agregado que esses produtos e serviços lhes possam oferecer.

A informação existe independente de sua forma ou de qualquer processo interpretativo de sua mensagem pelo seu receptor, ela está por toda parte, mas como diz Capurro (2007, p. 166) "A mensagem pode adquirir significado, se e somente se, tiver a sua informação processada por um receptor." Para a aquisição desse significado traduzido em conhecimento é primordial que seu usuário processe a mensagem e que ela seja realmente algo que dela ele necessitasse. Na mesma obra, Capurro (2007, p. 172) comenta sobre a existência da informação relativa ao conhecimento "[...] mesmo se a informação for vista como algo existindo independente do conhecimento do receptor, isto não implica necessariamente que a informação seja algo absoluto."

A informação disponibilizada pelas IFES e para atender os objetivos dessas instituições, necessita se mais do que espaço físico, mas de ações que compreenda as inter-relações dentro desses espaços. Para Baughman (apud VERGUEIRO, 1993), existe uma relação entre os componentes que resultará no desenvolvimento de coleções, sendo eles o planejamento, implementação e avaliação de coleções:

O desenvolvimento de coleções irá constituirse, então, no entrecruzamento de planejamento, implementação e avaliação de coleções, que serão assim definidos:

a) planejamento da coleção - é um projeto para a acumulação de documentos afins, da maneira determinada pelas necessidades, propósitos, objetivos e prioridades da biblioteca;

b) implementação da coleção - trata do processo de tornaros documentos acessíveis para uso;

c) avaliação da coleção - envolve seu exame e julgamento em relação aos objetivos e propósitos estipulados (VERGUEIRO, 1993).

Se formos analisar a história da Biblioteconomia, o planejamento de coleções está previsto nas cinco Leis de Ranganathan, onde:

1. Os livros são para usar

2. A cada leitor seu livro

3. A cada livro seu leitor

4. Poupe o tempo do leitor

5. A biblioteca é um organismo em crescimento

Desta forma, não há como manter um acervo em uso sem que a coleção esteja adequada ao leitor, para que ele possa recuperar a informação desejada e da forma que melhor se adequar as suas necessidades e, assim, para manter um acervo que sempre atenda aos usuários, ele deve estar em constante processo de renovação. Como observado no texto de Ranganathan (2009, p. 241), quando ele diz que "[...] a Quinta Lei enuncia o princípio fundamental que deve 
presidir ao planejamento e organização das bibliotecas". Mas adiante ele continua:

A Quinta Lei chama nossa atenção para o fato de a biblioteca, como instituição, possuir todos os atributos de um organismo em crescimento. Um organismo em crescimento absorve matéria nova, elimina matéria antiga, muda de tamanho e assume novas aparências e formas. [...] O que persistiu através de todas essas mudanças de forma foi princípio essencial da vida. $\mathrm{O}$ mesmo acontece com a biblioteca (RANGANATHAN, 2009, p. 241).

A busca pela informação vem causando mudanças nas formas de constituição dos acervos, são os avanços tecnológicos os maiores responsáveis por tais mudanças. $\mathrm{Na}$ obra de Floridi (1999), ele discute a evolução tecnológica e seu uso desde o simples manuseio em tarefas rotineiras ao uso para elaboração e execução das viagens espaciais, da necessidade diária dessas Tecnologias da Informação e Comunicação (TICs) no cotidiano das pessoas e aqui, creio que aqui também estão inclusas as atividades das bibliotecas.

As várias formas de recuperação da informação e os vários suportes aos quais ela pode estar inserida acabam por fazer com que o gestor passe a melhor planejar a manutenção de seus acervos, o autor Johnson, (1994 apud KHAN; KHAN, 2010, p.8) afirma que "Bibliotecas sem políticas de desenvolvimento de acervo são como negócios sem planos de negócios".

As pessoas estão sempre em busca de alguma informação, de alguma solução para seus questionamentos, deve-se oferecer ao usuário formas de acessá-las, fator necessário para o desenvolvimento ético de políticas de seleção e disseminação do acervo, conforme Carvalho explica:

$\mathrm{Na}$ sociedade da informação os indivíduos devem ser capazes de conhecer suas necessidades de informação, acessá-las eticamente. Nesse sentido estudos da Ciência da Informação têm atribuído destaque à figura do indivíduo enquanto usuário da informação (CARVALHO, 2008, p. 13).

Ainda na mesma obra, o autor relata sobre a necessidade de "entender as necessidades e comportamentos de uso da informação dos usuários para promover a esses a educação das competências necessária". A necessidade de informação e de adequação do material para as atividades acadêmicas leva os usuários a buscarem alternativas além das fronteiras das IFES.

As coleções da FAC que compõem os repositórios da Biblioteca Central (BCE) da UnB, vem de encontro com essas mudanças tecnológicas e de atendimento as necessidades de usuários específicos, facilitando a disseminação dentro e fora da instituição, ao mesmo tempo que preserva a memória da unidade acadêmica.

Repositórios digitais são coleções digitais construídas para diferentes propósitos. $\mathrm{O}$ repositório de Coleções Especiais da BCE que passou a abrigar os materiais produzidos pelas disciplinas da FAC, são baseados em coleções que não se enquadram como produtos de finalização de cursos ou como material científico. Os repositórios institucionais já implantados na BCE são baseados na política de Open Acess para fácil acesso de seu público alvo. Um repositório digital tem como objetivo guardar e possibilitar o acesso de produções científicas de uma instituição, seja de uma área específica ou multidisciplinar, como por exemplo toda a produção feita pelo corpo docente dentro da UnB.

O RIUnB tem como objetivos armazenar, preservar, divulgar e garantir acesso à produção científica e acadêmica da Universidade de Brasília em formato digital; proporcionar visibilidade à produção científica da instituição; apoiar as atividades de pesquisa e criação do conhecimento científico e apoiar o processo de ensinoaprendizagem por meio do acesso facilitado ao conhecimento (SAYÃO, 2009, p. 335)

Repositórios institucionais são feitos para preservar o conteúdo de uma instituição, incentivando a produção científica dentro da instituição, dando maior visibilidade para esses trabalhos produzidos e também sendo um ótimo dado de avaliação de produção científica dentro da instituição. Repositórios institucionais são um recurso que gera prestígio para a instituição que cria e gerencia. Além de preservar, armazenar, classificar e distribuir a informação digital dentro, e as vezes fora, da instituição. 
Os repositórios são muitas vezes confundidos com as bibliotecas digitais, a definição de biblioteca digital é a digitalização e a possibilidade de acesso digital de materiais físicos, o que nem sempre um repositório pode oferecer, já que seus materiais, em maioria, não têm versões físicas, por isso as bibliotecas digitais são uma extensão de uma biblioteca física. Embora os serviços sejam parecidos podemos dizer que a biblioteca digital é um repositório, mas um repositório nem sempre será uma biblioteca digital (MASSON, 2008). Neste caso, as coleções da FAC que compõem o repositório de Coleções Especiais da BCE, tem tanto materiais digitalizados como natodigitais. Se faz necessária a construção de uma coleção que supra o crescimento de informações úteis que apoiem e enriqueçam a formação discente, esse deve ser o propósito do desenvolvimento de coleções, sobre o qual as bibliotecas precisam ter diretrizes claras para que forneçam os melhores materiais informacionais para estruturar os seus acervos.

\subsection{OPEN ACESS}

Para melhor entender a forma de disponibilidade e acessibilidade que são oferecidos pelos repositórios da $\mathrm{BCE} / \mathrm{UnB}$, esses são baseados na política de Open Acess, ou seja no livre uso do arquivo, como cópia e impressão e alguns outros direitos garantidos através do Creative Commons. O Open acess, ou Acesso aberto, não significa que o arquivo seja de graça, porém não excluindo a possibilidade, apenas que o arquivo pode ser acessados e não será limitado a apenas poucos usuários, sendo assim disseminado dentro da comunidade acadêmica, além de incentivar a produção científica por ter material para pesquisas. Quanto maior o número de trabalhos que podem ser acessados, maior a qualidade de trabalhos futuros que usarem esses trabalhos para continuidade de suas pesquisas.

Então basicamente o Open Acess é a possibilidade de permitir que todo e qualquer material no repositório seja acessado e usado sem discriminação, não limitando o número de pesquisas e nem de resultados. Instituições como a UnB produzem muito conteúdo que deve ser disseminado e acessado, além demonstrar os resultados das pesquisas e avanços que a instituição produz.

\subsubsection{Direito Autoral e Creative Commons}

A lei de direito autoral brasileira é a mais rígida conhecida atualmente, ela dá ao autor o direito de decidir qualquer tipo de uso que sua obra pode ter na mão de terceiros, existem vários tipos de direito autoral, como copyright, copyleft e creative commons.

O Creative Commons (CC) constrói a linha de equilíbrio entre a pessoa que possui o direito moral de um obra e uma pessoa que deseja usufruir dessa obra, ou seja garante o direito moral do autor sobre suas criações. A função do CC é fornecer autorizações personalizadas sobre essas obras intelectuais, como cópia, redistribuição, edição etc. Todas as autorizações do $\mathrm{CC}$ têm como foco manter o direito do autor, mas permitindo que esse trabalho seja distribuído e utilizado. Essa é a política adotada pela Universidade de Brasília, para a formação de seus repositórios.

Mas na UnB, através da Resolução do Conselho de Administração n ${ }^{\circ} 005$, de 26 de novembro de 1998, dispôs a alocação e proteção dos direitos de propriedade intelectual, sendo reconhecido como a "Política de Propriedade Intelectual da Fundação Universidade de Brasília." (GHESTI et al., 2016, p. 28)

A UnB tornou-se detentora do direito patrimonial das obras intelectuais "[...] em decorrência da natureza do trabalho de membros da comunidade acadêmica ou com a utilização de recursos da UnB" (GHESTI et al., 2016, p. 28)., devendo preservar o direito moral do autor da obra intelectual.

Foi identificado que a responsabilidade pela regulamentação das políticas de inovação na UnB é o Centro de Apoio Desenvolvimento Tecnológico (CDT), atuando como um NIT (previsto em Lei), sendo assegurado pelo Ato da Reitoria $\mathrm{n}^{\circ} 0544$, de 2 de maio de 2011, no qual o coloca como unidade gestora, podendo executar atos de gestão orçamentária, financeira e patrimonial.

Assim, as coleções da FAC, sob a organização do CeDoc e guarda da BCE, foram construídas com base no creative commons, mas sem desconsiderar as normas internas estabelecidas.

\section{A ORGANIZAÇÃO DA COLEÇÃO FAC}

Com a falta de consenso ao que se refere constituir as "Coleções Especiais", deve-se considerar que esse tipo de coleção se 
desenvolve de maneira muito particular devido às diferentes realidades em que cada instituição e características de sua comunidade. Miranda (2007, p. 87) ressalta que as necessidades informacionais da comunidade que um centro de informação atende para diferenciar a classificação de suas coleções:

A formação, desenvolvimento e organização do acervo [de bibliotecas] devem ser encarados como um processo permanente no qual as atividades de seleção, aquisição e avaliação de materiais devem permanecer em contínua sintonia com as necessidades de informação da comunidade de usuários (MIRANDA, 2007).

Além da parceria iniciada entre FAC e BCE, para a preservação das coleções discentes através da inserção dos produtos nos repositórios da instituição, temos ainda:

A) Elaboração de manuais com a descrição das técnicas e sobre produtos virtuais abertos, para promover o aprender a aprender, voltados a orientar o uso e desenvolvimento de ferramentas digitais para acesso e disseminação da informação, sob a perspectiva da comunicação em rede, a partir do CeDoc, hub importante da Rede FAC.

B) Com a aplicação de uma pesquisa em cada turma da disciplina de Comunicação, Informação e Computação (CIC) da
FAC/UnB, que ocorreu em 2017 e no primeiro semestre de 2018, foi possível avaliar as competências para o aspecto instrumental de informação e de comunicação para busca, acesso e uso da informação - jornais, monografias, produtos de comunicação - e também avaliar a capacidade deste público em utilizar as redes de informação. Estão sendo definidos, com a participação de outros professores da faculdade, modelos que visam atender as necessidades e capacidades dos indivíduos que compõem a rede.

Ao propor um modelo próprio para o armazenamento e consequentemente a preservação da memória da unidade acadêmica vislumbrou-se a possibilidade em melhor atender os potenciais usuários dessas redes que estão sendo construídas em um contexto multidisciplinar.

Diante desse quadro surgiu o Centro de Documentação como um projeto transdisciplinar envolvendo áreas da comunicação, ciência da informação e computação com o objetivo de auxiliar o desenvolvimento científico dos cursos da área de Comunicação. O criar um modelo de fluxo próprio, (Figura 1), independente dos tipos de produtos que a unidade dispõe para o acervamento, intenciona-se facilitar $\mathrm{o}$ entendimento aos processos de formação desse acervo.

Figura 4: Fluxo para envio de produtos ao CEDOC

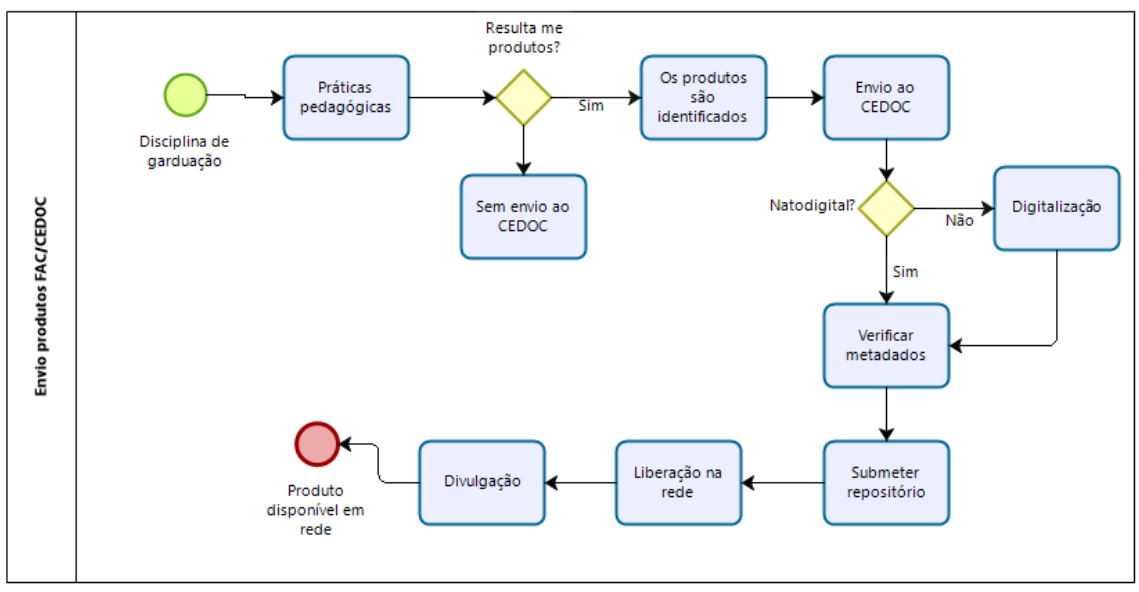

Fonte: PERES, MR

Todas as disciplinas que geram produtos de suas práticas pedagógicas, identificam essa produção não apenas enquanto disciplina, professor e ano, mas com a identificação dos discentes envolvidos. Se o produto, mesmo que com resultados em suporte físico (jornal, 
revista, DVD e outros), já é natodigital, eles apenas seguem para a verificação das informações que irão compor os metadados e serão inseridos no repositório de coleções especiais, em coleção própria para o produto, após nova verificação o produto é liberado em rede e o CEDOC usa as redes sociais para a divulgação no novo material.

\section{CONSIDERAÇÕES FINAIS}

A mente humana faz associações automáticas, consegue relacionar fatos e vivências, isso fica evidenciado na obra de Lévy "Quando ouço uma palavra, isto ativa imediatamente em minha mente uma rede de outras palavras, de conceitos, de modelos, mas também de imagens, sons, [...]". E ele completa que "Mas apenas os nós selecionados pelo contexto serão ativados com força suficiente em nossa consciência." (LEVY, 1993, p. 23). Os repositórios surgem com essa perspectiva, de nos levar a assuntos diversos dentro das áreas de interesse do usuário. Foi com essa visão que o espaço físico do CeDoc foi construído com recursos do Reuni, embora haja registro desde os anos 1980 de projetos de pesquisa envolvendo um espaço de memória na Faculdade. Somente nos últimos anos foi possível pensar na concretização da implantação de um serviço de preservação da produção acadêmica da FAC.

Este projeto permitiu conhecer a produção de estudantes da FAC nestes 52 anos de existência, o que representa a curadoria da informação sobre a Universidade de Brasília sob a ótica de jovens em formação nas carreiras de jornalismo, publicidade, rádio e cinema. Vale ressaltar que muitos destes documentos, que contam a história da UnB, estão sob a guarda exclusiva da FAC e ainda carecem de tratamento para a divulgação. Esta história da Universidade é, por certo, também a história de Brasília.

As primeiras turmas conseguiram identificar os tipos de documentos e as necessidades dos usuários. Em 2017 foram iniciadas as ações para organização do CeDoc com a contratação de 02 estagiários e a inclusão de 02 bolsistas através de projeto de extensão aprovado na instituição, também são consideradas as atividades com os alunos da disciplina, com adequação de espaço e estudos das ferramentas compatíveis com as necessidades do projeto, além do financiamento da FAP-DF que possibilitou o envolvimento de bolsistas e a divulgação dos resultados.

$\mathrm{O}$ projeto busca relacionar transdisciplinarmente entre os campos da Ciência da Informação, da Computação e Comunicação, para resolver problemas que envolvem armazenamento, acesso e uso de redes de documentos e de repositórios de informação, produzidos por redes de pesquisadores da faculdade e outras redes de interesse mediado por dispositivos digitais fixos ou móveis.

$\mathrm{O}$ espaço do $\mathrm{CeDoc}$ ainda tem funcionamento regular para atendimento externo, além de atender por demandas através de e-mail ou telefone. $\mathrm{O}$ projeto propicia a possibilidade de acesso e uso, e, neste processo, dar acesso aberto às informações, dados e modelos desenvolvidos em repositórios vinculados à $\mathrm{BCE}$.

\title{
THE SPECIAL DIGITAL COLLECTIONS: THE CEDOC CASE OF UNB FACULTY OF COMMUNICATION
}

\begin{abstract}
The Documentation Center of the Faculty of Communication of the University of Brasilia (FAC) brings together the academic and experimental production of the Faculty from a project to build a laboratory space, transdisciplinary, for research and the creation of a proposal research. Management of the Memory in Communication and Information of the Faculty of Communication. The information actions for the creation of a special collection in the repositories of the ECB, which could be possible for a communication, information and computing discipline: fundamentals and application. The preservation actions are: 1. Organization and digitalization of journals of Campus Reporter Campus Reporter; 2. Organization and
\end{abstract}


digitization of the printed campus newspaper, the newspaper editor; 3. Free Bookreading room for shared use and maintenance. Preparation of standards, tutorials and manuals for the performance of activities. The project as a whole is still in the implementation phase.

Keywords: Information; Computing; Communication; Information Repositories; Special Collections.

\section{REFERÊNCIAS}

CAPURRO, Rafael; HJORLAND, Birger. O Conceito de Informação. Perspectivas em Ciência da Informação. v.12, n. 1, jan./abr. 2007.

\section{CARVALHO, F. C. Educação e estudo de usuários em bibliotecas universitárias brasileiras: abordagem centrada nas competências em informações. 145p. Dissertação (Mestrado em Ciência da Informação) - Universidade de Brasília-UnB, 2008.}

FLORIDI, Luciano. Philosophy and

computing. London: Routledge, 1999.

GHESTI, Grace Ferreira et al (Ed.). Conhecimentos básicos sobre propriedade intelectual. Brasília: Centro de Apoio Ao Desenvolvimento Tecnológico da Universidade de Brasília, 2016. 153 p.

Disponível em:

<http://www.cdt.unb.br/pdf/programaseprojet os/nupitec/PROPRIEDADE\%20INTELECT

UAL.compressed.pdf $>$. Acesso em: 20 nov. 2017.

KHAN, S. I.; KHAN, M. A.

Desenvolvimento de acervo na biblioteca Maulana Azad (AMU) e na Biblioteca Central da Universidade de Delhi: um estudo comparativo. BJIS, Marília (SP), v.4, n.2, p.3-21, jul./dez. 2010. Disponível em: <http://www2.marilia.unesp.br/revistas/index. php/bjis/index>. ISSN: 1981-1640. Acesso em: 10 ago. 2011.

LÉVY, Pierre. As tecnologias da

inteligência. $O$ futuro do pensamento na era da informática. Rio de Janeiro: Ed. 34, 1993. Disponível em: <

https://wp.ufpel.edu.br/franciscovargas/files/2 015/03/LEVY-Pierre-1998-Tecnologias-da-

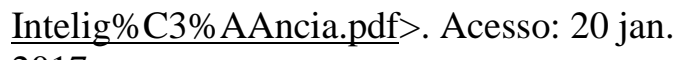
2017.

MAZZONI, A. A. et al. Aspectos que interferem na construção da acessibilidade em bibliotecas universitárias. Ciência da Informação, Brasília, v.30, n. 2, p. 29-34, 2001. Disponível em: <http://revista.ibict.br/index.php/ciinf/article/ view/184/163>. Acesso em: 10 jan. 2010.

MIRANDA, Ana Cláudia Carvalho de. Formação e desenvolvimento de coleções em bibliotecas especializadas. Inf. \& Soc.:Est., João Pessoa, v.17, n.1, p.87-94, jan./abr., 2007. Disponível em: <

http://www.ies.ufpb.br/ojs2/index.php/ies/arti cle/view/463/624>. Acesso em: 05 nov. 2010.

MASSON, Sílvia Mendes. Os Repositórios digitais no âmbito da Sociedade Informacional. Prisma.com, Porto, v. 7, p.105-152, 2008. Universidade do Porto, Faculdade de Letras.

http://dx.doi.org/10.21747/16463153.

Disponível em:

<http://ojs.letras.up.pt/index.php/prismacom/a rticle/view/2079>. Acesso em: 10 set. 2017.

MIRANDA, A.; SIMEÃO, E. Da

Comunicação Extensiva ao hibridismo da Animaverbivocovisualidade (AV3). Inf. \&

Soc.: Est., João Pessoa, v. 24, no 3, p. 49 62, set./dez. 2014. Acesso em: 20 jan. 2017.

Disponível em:

<http://www.ies.ufpb.br/ojs/index.php/ies/arti cle/view/19075/12401;

RANGANATHAN, Shiyali Ramamrita. As cinco leis da biblioteconomia.

Brasília:Briquet de Lemos/Livros, 2009.

SAYÃO, Luis et al. Implantação e gestão de repositório institucionais: políticas, memória, livre acesso e preservação. 
Pesquisa em Andamento

EDUFBA, 2009. Disponível em: <

http://www.repositorio.ufba.br/ri/bitstream/uf ba/473/3/implantacao_repositorio_web.pdf $>$

VERGUEIRO, Waldomiro de Castro Santos. Desenvolvimento de coleções: uma nova visão para o planejamento de recursos informacionais. Ciência da Informação, Brasília, v. 22, n. 1, 1993. Disponível em: <http://revista.ibict.br/index.php/ciinf/article/ view/1208/849>. Acesso em: 12 fev. 2011. 